\title{
Using suite energy-use and interior condition data to improve energy modeling of a 1960s MURB
}

\author{
Touchie, Marianne F., Pressnail, Kim D. \\ Version Post-print/accepted manuscript \\ Citation Touchie, Marianne F., Pressnail, Kim D. (2014). Using suite energy-use \\ (published version) and interior condition data to improve energy modeling of a 1960s \\ MURB. Energy and Buildings; 80, pp. 184-194, doi: \\ 10.1016/j.enbuild.2014.05.014. \\ Additional publisher The final version of this article is available from Elsevier at \\ information https://doi.org/10.1016/j.enbuild.2014.05.014. \\ Copyright/License \\ (c) (i) $\odot$ This work is licensed under the Creative Commons \\ BY NC ND Attribution-NonCommercial-NoDerivatives 4.0 \\ International License. To view a copy of this license, visit \\ http://creativecommons.org/licenses/by-nc-nd/4.0/.
}

\section{How to cite TSpace items}

Always cite the published version, so the author(s) will receive recognition through services that track citation counts, e.g. Scopus. If you need to cite the page number of the author manuscript from TSpace because you cannot access the published version, then cite the TSpace version in addition to the published version using the permanent URI (handle) found on the record page.

This article was made openly accessible by $U$ of $T$ Faculty. Please tell us how this access benefits you. Your story matters. 
Using Suite Energy-Use and Interior Condition Data to Improve Energy Modeling of a 1960's MURB

Marianne F. Touchie (corresponding author), Department of Civil Engineering, University of Toronto

Kim D. Pressnail, Department of Civil Engineering, University of Toronto

Corresponding author contact details: +14166686408, marianne.touchie@mail.utoronto.ca. Department of Civil

Engineering, University of Toronto, 35 St. George Street, Toronto, Ontario, Canada, M5S1A4

\begin{abstract}
:
Energy modeling is a useful tool for evaluating the performance of contemplated building energy retrofit measures. Traditionally, energy models are developed using data collected from building floor plans and site visits and are then calibrated using utility bills. In the work presented here, an energy model for an existing multi-unit residential building (MURB) was developed using this traditional approach. Next, a refined approach was taken. Using data gathered from a suite-based monitoring program, input data uncertainties in the energy model were addressed. Data from one year of monitoring were assembled to characterize the actual building performance and to calibrate this refined energy model. In order to identify which parameters could be used to improve the model accuracy, the output of this refined model was compared to the output from the traditional modeling approach. It was found that the interior temperature measurements and the sub-metered suite electricity use were the most beneficial in refining the energy model. However, other data collected including window operation and differential air pressures were useful for determining how the building was operating. The use of a local weather file generated from a roof-top weather station has also been discussed.
\end{abstract}

\title{
Key words:
}

multi-unit residential building, energy model, sub-metering, building monitoring

\section{Background}

Many North American jurisdictions are striving to improve the energy standards for new buildings. However, to significantly reduce the energy-use and the related environmental burden of our building stock, existing buildings 
must be energy retrofitted. Planning an energy retrofit usually begins with an assessment of the building condition and the collection of energy-use data. In recent years, the municipal government in Toronto, Canada, has begun this assessment phase for an important City asset: the thousands of multi-unit residential buildings (MURBs) that provide an estimated $55 \%$ of dwellings in the City [1]. The work here is presented in the context of Toronto MURBs, but the approach and the findings are applicable to other cold-climate urban regions.

The assessment process involves generating an estimate of the expected energy savings associated with particular retrofit measures. To do this, a building energy-use model is developed for the subject building and then calibrated using utility bill data. Once calibrated, the model can be used to assess potential energy and greenhouse gas emission savings associated with various retrofit measures. However, the calibration of models that accurately predict energy-use in buildings is somewhat of an art [2]. It is well recognized that just because a model has been calibrated using gross building energy data, it does not necessarily follow that accurate predictions of retrofit energy savings will result. While there is uncertainty in any computer simulation, an indication that the calibrated model may not be an accurate predictor of retrofit energy savings occurs when the predicted energy end-use components or the resulting interior conditions do not match observations of the existing building. Thus, confidence in the accuracy of the modeling output increases when the calibrated model output not only matches the utility data, but it also accurately predicts the observed energy end-use components and the interior conditions.

Unfortunately, energy-use patterns and interior conditions in MURBs are not as well documented as commercial buildings. Given the sparse data for MURBs and the complexity and interrelated nature of residential energy consumption [3], an energy modeler seeking to improve the calibration of an energy model must make many assumptions. Such assumptions, particularly with regard to occupant behavior and interior conditions, may lead to inaccurate retrofit energy savings predictions.

\section{Study Approach}

An energy model based on information from building floor plans and audit reports was developed. Utility bill data were calendarized and weather normalized to the standard weather data available in the energy modeling software. Then, the model was calibrated using these processed utility data. Herein, this model is known as the 
"Traditional Approach." To reduce the level of uncertainty associated with the assumptions used in the Traditional Approach model, a detailed monitoring program of an existing MURB was undertaken. Energy consumption, interior condition, and local weather data from one year of monitoring were assembled to characterize the actual building performance and to calibrate an energy model based on the monitored data. This model is referred to as the "Refined Approach." After development and calibration of the two energy models, the modeled suite temperatures and energy end-uses were compared with the monitored data. This novel approach was taken to demonstrate the potential for improvement in the accuracy of the energy model output compared to a traditional approach where the model is calibrated with gross utility data. The monitored parameters which were most useful for improving the model accuracy are discussed.

\section{Subject Building}

Over $40 \%$ of MURBs in the City of Toronto were constructed during the 1960s and 1970s [1] and MURBs of this vintage exhibit similar features such as exposed floor slab edges, air-leaky exterior envelopes, pressurized-corridor make-up air supply, baseboard heating and no central air conditioning. In an attempt to maximize the applicability of the findings of this work, a subject MURB in Toronto with similar characteristics was selected. The selected building is 20-stories and was constructed in 1968. It is one of two student family housing buildings at the University of Toronto and is similar to many Toronto MURBs of this vintage. Most student residences on campus have dormitory-style accommodation. This building consists of self-contained one- and two-bedroom apartment units occupied by couples and young families. Basic building details are provided in Table 1.

\section{Energy model development}

The Quick Energy Simulation Tool (eQUEST), developed by the U.S. Department of Energy (DOE), was used to model the subject MURB in this study. This whole-building energy simulation program was chosen because, in addition to modeling new construction, it is commonly used in industry for retrofit measure assessments.

First, building information known with some certainty was entered into the model. Most of these building details were determined from floor plans, an audit report, interviews with the building manager, and site visits. These data included occupant density; fenestration ratio per elevation; building envelope details; boiler and tank 
capacities and quantities; and fan and pump power. Then, values for less certain parameters were estimated. For unknown parameters such fan air flow rates and envelope air leakage, estimates were made using values found in the literature [4][5]. The modeled fan air flow rate for the whole-building corridor supply air was $7.5 \mathrm{~m}^{3} / \mathrm{s}$ and the modeled air leakage rate was $1.5 \mathrm{~L} / \mathrm{s} / \mathrm{m}^{2}$ of exterior wall area. These parameters were held constant for both the Traditional and Refined Approach models. Other unknown parameters such as lighting and plug loads, DHW consumption, zone temperatures and loop capacities were systematically varied in order to calibrate the model.

\section{Traditional Approach}

By comparing preliminary models based only on building inputs with those that have been calibrated using monthly utility data, many researchers [5][6] have shown the value of energy model calibration. Therefore, once the basic model was developed, as described in Section 4, it was calibrated using energy consumption data from utility bills.

\subsection{Energy consumption}

Without access to a complete weather file that matches the period covered by the available utility bill data, the modeler must first normalize the billing data to the local area standard weather year used by the energy modeling program. In this case, the Toronto weather file in eQUEST is based on the Canadian Weather for Energy Calculations (CWEC) standard weather year data gathered at the City's main airport.

Historical utility billing data from 2009 to 2013 were used for the normalization process. These data were first calendarized to generate consumption based on each calendar month rather than between arbitrary meter reading dates, as described by Touchie et al. [1]. Then, natural gas data were plotted against heating degree-days (HDDs), assuming a base temperature of $18^{\circ} \mathrm{C}$, and the line of best fit was determined. The predicted CWEC standard year natural gas consumption was determined using the equation of the line-of-best-fit and the monthly HDD totals in the standard weather year. No significant correlation was found between electricity consumption and heating or cooling degree-days so the average electricity consumption for each month of the years of historical data was taken as the "standard" consumption (e.g. standard year April consumption equalled the average consumption for April 2009-2013.) The resulting weather-normalized annual energy consumption profile shown in 
Figure 1 and the energy use intensity of the subject building following this normalization was $374 \mathrm{ekWh} / \mathrm{m}^{2}$. This building energy use intensity was significantly greater than $300 \mathrm{ekWh} / \mathrm{m}^{2}$, the median energy use intensity of a citywide survey of Toronto MURB energy-use [1]. However, the subject building energy use intensity was still well within the range of the sample from this Toronto study $\left(90-530 \mathrm{ekWh} / \mathrm{m}^{2}\right)$. Further, it is the operation of buildings such as this that need to be better understood. Such buildings provide the greatest opportunity for performance improvement since they are performing at the upper end of this spectrum of energy use intensity.

The components of energy-use were analyzed further. The base natural gas load of the subject building ( $25 \%$ of total energy-use) is similar to that in a typical MURB (24\%) [7]. However, the proportion of natural gas (76\%) and electricity (24\%) varies significantly from the published energy mix of apartment buildings in Ontario: $66 \%$ natural gas and $34 \%$ electricity [8]. While the majority of buildings are heated with natural gas, the provincial average is influenced by the number of electrically heated buildings. As the subject building is heated with natural gas, this may explain some of the variation from the provincial average. The higher proportion of natural gas consumption can usually be attributed to the lack of insulation in the envelope and the efficiency of the natural gas space and DHW heating equipment.

\subsection{Calibration using utility bills}

Many energy model calibration techniques have been developed such as those reviewed and proposed by Reddy [2][9] and Hubler et al. [10]. For this work, a calibration procedure similar to that outlined by Hubler et al. [10] was followed. Calibration of the Traditional Approach model began with adjusting the DHW consumption per occupant to $265 \mathrm{~L}$ per day to match the average natural gas consumption for the three months in which there was no space heating (June, July and August). The consumption resulting from the model calibration was compared to the literature to ensure the modeled value was reasonable [11][12].

The remaining natural gas and electricity consumption calibration was carried out iteratively as waste heat from electricity loads affects the heating and cooling requirements of the building. To begin, lighting and plug loads by zone were scaled up from the default values to match the electricity consumption in the shoulder seasons. Next, the set point temperatures and heating loop capacities were adjusted slightly to ensure that the zones were 
modeled at the default set point temperatures and that the modeled natural gas consumption closely matched the weather-normalized actual consumption. The natural gas space heating boilers were modeled at $95 \%$ efficiency as the original boilers were recently replaced with new, high-efficiency equipment. Finally, the cooling capacity was adjusted to match the summer electricity consumption.

The resulting modeled natural gas and electricity consumption are shown in Figure 2 along with the actual consumption normalized to the CWEC standard weather year.

The American Society of Heating, Refrigeration and Air Conditioning Engineers' (ASHRAE) Guideline 14, Measurement of Energy and Demand Savings [13], recommends and describes the use of two statistical techniques to compare the modeled and measured data. The normalized mean bias error (NMBE) is used to determine the difference between the measured and modeled values on an annual basis. However, since the positive and negative errors in the NMBE cancel out thereby reducing the NMBE, a second technique was also employed. The coefficient of variation of the root mean square error (CVRMSE) measures how well the modeled values fit the measured data. Improved model calibration is indicated by a lower CVRMSE and NMBE. Guideline 14 states that the maximum allowable values of CVRMSE and NMBE, when using monthly data, are $+15 \%$ and $\pm 5 \%$, respectively [13]. The CVRMSE and the NMBE for natural gas were $+12 \%$ and $+2.4 \%$, respectively, while the CVRMSE and NMBE for electricity were $+4.9 \%$ and $+1.2 \%$, respectively. As both measures of model fit were within the acceptable ranges, the model was considered appropriately calibrated.

\section{Refined Approach Methodology}

A building monitoring program was designed and implemented between April $26^{\text {th }}, 2012$ and April $25^{\text {th }}, 2013$. This monitoring program was developed to improve upon the results from the Traditional Approach, to reduce model uncertainty and to better represent the actual building performance. The program involved observation of three key areas: local weather, energy consumption and suite interior conditions. Table 2 provides a summary of the monitoring program encompassing these three areas. In the remainder of this section, the weaknesses of the Traditional Approach are identified for each area and then the Refined Approach is introduced. 


\subsection{Weather Data}

The normalization process used in the Traditional Approach introduces error, through both the calendarization and the estimation of the energy performance in the standard weather year. Furthermore, standard weather year data are typically based on 30-year historical averages. As the climate changes, these weather data may no longer be representative of the current and future heating and cooling degree-day profiles. This could result in retrofit savings estimates that are in error. To address these issues, a weather station was placed on the roof of the subject building to record the local weather data. The data collected in 15-minute intervals were then used to generate a custom weather file for use in the eQUEST simulation. In this way, actual weather conditions could be paired with actual energy consumption rather than relying on weather-normalized values.

\subsection{Energy Consumption}

Many researchers [17][18][19] have investigated building, and specifically MURB, energy-use by monitoring energy consumption with much greater resolution than the data available from utility bills which were used in the Traditional Approach. Sub-hourly interval data can be used to characterize daily and hourly energy consumption patterns which could reveal the impact of loads like the window A/C units, for example. The monthly electricity consumption derived from subject building utility bills did not appear to be significantly influenced by the use of the window air-conditioning $(\mathrm{A} / \mathrm{C})$ units installed in $34 \%$ of the suites. So, to supplement the energy consumption data from utility bills, electricity and natural gas data were collected from the subject building in 15-minute intervals. Additionally, the electricity consumption for several suites was sub-metered in order to estimate the split between suite-based and common area electricity use which was not available from the bulk-billed data used in the Traditional Approach. A single meter was used to collect pulse outputs from the building electricity meter and the building natural gas meter as well as the electrical current from the circuits of the sub-metered suites.

\subsection{Suite Conditions Comparison}

Regardless of how well the model can predict energy-use, it should also generate interior conditions similar to the actual building. Kavgic et al. [20] indicated that energy models often use standard air temperatures, such as the model default air temperatures used in the Traditional Approach, instead of air temperatures based on empirical data. However, interior air temperatures are not just the product of thermostat settings but they are also a 
product of occupant behaviour as demonstrated by Jian et al. [21] in their observation of the effect of window operation on suite temperature.

To determine the suite conditions for the Refined Approach model, a number of parameters were monitored. Interior air temperature and relative humidity were captured along with the temperature of the radiator fins to determine how the heating system responded to the interior and exterior conditions. Displacement sensors were used to observe when occupants opened windows and balcony doors. Finally, the effects of the ventilation and exhaust systems and stack effect were monitored using differential pressure sensors across the exterior envelope, between the suite and the corridor, and at the bathroom and kitchen exhaust fans.

\subsubsection{Monitoring Equipment}

At the project outset, six identical suites were sought: one located at the top, middle and bottom of both the north and south facades. Constrained by the location of the suites of the volunteer study participants, the wireless technology used to transmit the data, and the project budget, the selected suites were clustered together in the upper-middle part of the building on floors 11 to 15. A total of seven suites were monitored for a one-year period.

The in-suite monitoring system included of a series of wireless data loggers/transmitters with built-in temperature and relative humidity sensors. Three suites were "fully-monitored" with temperature, relative humidity, displacement and differential pressure sensors. Four additional suites were "partially-monitored" with temperature and relative humidity sensors only. Temperature and relative humidity sensors were also located in the corridors of the $3^{\text {rd }}, 11^{\text {th }}, 12^{\text {th }}, 15^{\text {th }}$ and $19^{\text {th }}$ floors. The approximate location of the data loggers and sensors in the fully-monitored suites is provided in Figure 3 and the details of the equipment used, including the power meter and weather station, are provided in Table 2. Due to the power panel configuration in the building, the submetered electricity consumption, discussed in Section 6.2 , was only captured for the suites on the $11^{\text {th }}, 12^{\text {th }}$ and $14^{\text {th }}$ floors.

\section{Refined Approach Data Analysis and Discussion}

Here the differences between the Traditional and Refined Approach models are compared in terms of the weather file used as well as the energy consumption and suite condition data. 


\subsection{Weather Data Comparison}

Table 3 shows the total heating and cooling degree-days from the standard weather file, the subject building weather station data and the weather data collected from the City's main airport during the monitoring period. Clearly the monitoring period data are warmer than the standard weather year data. Furthermore, the subject building weather station data shows that the inner-city location of the subject building was warmer than the Toronto airport during the monitoring period. This means that the energy model based on the Traditional Approach will have a higher variable natural gas load and lower variable electricity load compared to the model based on the Refined Approach. Section 9 describes the magnitude of the impact of these differences in energy consumption.

\subsection{Comparison between utility bill data and monitored data}

Figure 4 demonstrates the difference between the monthly energy consumption data sources for natural gas and electricity, respectively. The utility bill data, which were normalized to the CWEC standard weather year, represent the Traditional Approach. Limited metered natural gas data were available during the monitoring period so this was supplemented with calendarized utility bill data from the monitoring period which were not weather normalized. Combined with the monitored electricity consumption, these data from 2012-2013 represented the Refined Approach. The greater number of heating degree-days in the standard weather year data compared to the actual weather data from the monitoring period, have contributed to a higher natural gas consumption in the CWEC standard weather year profile.

After comparing the monitored and billed data, the monitored data were analyzed further to determine how different end-uses affected energy consumption. Bagge and Johansson [18] showed how the length of the data collection interval dramatically affects the observed peak consumption, so monitored data in intervals ranging from 15 minutes (shortest available in this project) to one day were examined to identify trends in the natural gas and electricity data. 


\subsubsection{Natural Gas}

Monthly whole-building natural gas consumption is presented in Figure 5 together with natural gas consumption data recorded in 15-minute intervals. The monthly natural gas consumption resulted in a profile that was expected. However, the 15-minute interval data profile suggests that the controls of the system might not be optimized given the wide range of consumption occurring during these short intervals.

After May 15, 2013, when the space heating system was turned off, the fluctuations in natural gas consumption due to the DHW boilers only (2 at 700kW each) can be observed. During this time, the consumption ranged between $0 \mathrm{~m}^{3}$ and about $15 \mathrm{~m}^{3}$ per 15 -minute interval. However, during the coldest month in the monitoring period, February, only one of three space heating boilers (each $860 \mathrm{~kW}$ ) appeared to be operating continuously while the other two frequently cycled on and off. While there are no peak charges for natural gas, frequent cycling can lead to more maintenance, premature failure of the boilers, reduced seasonal efficiency, and increased difficulties in maintaining set point temperatures [22].

There was no sub-metering of the natural gas equipment or the hot water delivered to each suite. Further, an assessment of the heating equipment performance including equipment efficiency was not carried out. Ideally the type of sub-metering as suggested by Cholewa et al. [23] could be used to accurately determine the heating system performance and then used to refine the model inputs. In this study, radiator fin surface temperature data were gathered in the fully-monitored suites to obtain a better understanding of how the heating system performed under different exterior conditions. Central hydronic baseboard heating systems, such as the one in the subject building, are turned on for the winter season, and turned off for the summer season. The transition period can be difficult to manage as exterior temperatures fluctuate during the shoulder seasons. Examination of the radiator fin surface temperature showed that there were periods when space heating was required but the system was not operational and other periods when the system was operating without a need for space heating.

\subsubsection{Electricity}

Figure 6 shows how the daily and monthly whole-building electricity data vary with the exterior temperature. The increase in winter consumption can be due to a number of factors including: shorter days that require more 
lighting; increased occupancy; the possible use of supplemental heating devices. The increase in summer electricity use is likely due to the use of suite air conditioners. While the relationship between temperature and electricity use is difficult to discern using the monthly billing data alone, as demonstrated by the utility bill analysis in the Traditional Approach, the availability of daily consumption data makes this relationship clearer.

Only $1.6 \%$ of the suites were electrically sub-metered because the metering was confined to only those residents on the $12^{\text {th }}$ floor power panel who granted permission to access these data. Nevertheless, within the small sample size, there were both one- and two-bedrooms suites as well as suites with and without A/C. As shown in Figure 7, there were large variations in suite-level plug and lighting loads, even during the winter when A/C would not be contributing to the electric load. Based on the average wintertime daily consumption normalized by floor area, the highest consuming suite used more than twice the lowest consuming suite which is consistent with the results from a CMHC study [17]. In the summer, when warmer temperatures prompted the use of window $A / C$ units, this difference grew to over four times.

The average electricity intensity of the monitored suites was $5.0 \mathrm{~W} / \mathrm{m}^{2}$ during the winter months and $5.6 \mathrm{~W} / \mathrm{m}^{2}$ in summer. Average summer electricity intensities ranged from $9.7 \mathrm{~W} / \mathrm{m}^{2}$ for suites with $\mathrm{A} / \mathrm{C}$ and $4.1 \mathrm{~W} / \mathrm{m}^{2}$ for those without. Using the number of suites with $\mathrm{A} / \mathrm{C}$ and the suite orientation, the monitored suite data were extrapolated in order to estimate the breakdown of electricity use in the building. From the extrapolation, it was estimated that the average annual suite electricity intensity is $45 \mathrm{kWh} / \mathrm{m}^{2}$. The total annual electricity intensity of the building is $64 \mathrm{kWh} / \mathrm{m}^{2}$ so, using the building floor plans and the suite-based estimate derived from extrapolation, the estimated electricity intensity of the common areas is $96 \mathrm{kWh} / \mathrm{m}^{2}$. On an annual basis, the suite loads represented $42 \%$ of the total building electrical load. It is important to view these findings in the context of the limited sample size and location of the sample within the building, as described.

Finding comparable energy intensities from other studies was challenging for a number of reasons including different building vintages, different equipment and different geographical locations. One study [24] had a comparable split between suite-based and common area while this load split in another study [17] was significantly different. Two Swedish studies [6][18] both showed lower total electricity intensities, but one of the 
buildings had a similar suite electricity intensity to the subject MURB. After comparing the electricity consumption of the subject building to other studies, it became clear that MURB electricity use can vary dramatically, both in magnitude and in the split between suite-based and common area loads. Without an understanding of the electricity end-use breakdown, the estimated impact of electricity reduction strategies is, at best, an educated guess. While the sub-metering of a selection of apartment loads was helpful in estimating the breakdown between suite-based and common area loads, further sub-metering of major equipment loads could have been used to refine the model further.

\subsection{Suite Conditions}

When collecting the suite condition data, various issues occurred which affected the quantity of the data acquired. Together with an increase in the sampling interval time, the actual amount of data collected was much less than originally envisioned. Of the total possible number of data points available for collection during the monitoring period, the proportion captured ranged from $14 \%$ to $61 \%$ depending on the suite.

While effort has been made to choose representative periods with similar quantities of observed data for comparison between suites, the results of the suite condition analysis must be viewed in the context of this sparse data. This section focuses on the temperature and relative humidity data but also includes a brief discussion of the other parameters investigated.

\subsubsection{Temperature and relative humidity}

Temperature and relative humidity can be used to assess how "comfortable" the suites are during different seasons. Although comfort is a relative term, ASHRAE has developed Standard 552010 Thermal Environmental Conditions for Human Occupancy [25] to provide a guide to what conditions are considered comfortable. Operative temperature is one of the parameters used to determine the comfort zone but these data were not collected from the subject building. Instead, dry bulb temperatures and an estimate of the mean radiant temperature (MRT) were used to approximate the operative temperature in the suites. This approach assumed a constant monthly MRT. It is important to note that assuming a constant MRT is not reflective of the actual conditions in the suite. This simplifying assumption means that daily variations which could cause thermal 
discomfort are not captured. Still, the analysis is carried out for illustrative purposes. In future monitoring programs, the MRT should be observed directly to improve the accuracy of this analysis. The comfort zone forms the basis of assessing the comfort conditions in the monitored suites in the subject building for one winter month and one summer month. Figure 8 shows the dry bulb temperature and relative humidity data for January and July, for the two suites with the largest quantity of data, with respect to limits of the comfort zone described in ASHRAE Standard 552010 . One suite is on the north side of the building and the other is on the south side.

The south-facing suite has higher living room temperatures in both January and July. This is likely due to solar gains. Using the comfort zone as a guide, it is clear that the south-facing suite 14B is uncomfortably warm during a large portion of July ( $82 \%$ of the data points collected). The south-facing suite also overheats in January ( $25 \%$ of the data points collected are warmer than the comfort zone). The average summer and winter interior suite temperatures were used to make appropriate adjustments to the suite zone temperatures in the energy model.

\subsubsection{Other parameters}

While temperature was really the only suite condition that could be directly incorporated in the energy model, analysis of the additional data collected revealed some interesting findings.

Window opening is an indication of occupants' dissatisfaction with their interior environment [21]. Through window displacement and temperature data, it was determined that residents of the subject building open their windows frequently, even during cold weather periods. These findings are similar to a study [20] of winter indoor temperatures and window operation in apartment buildings. During periods of cold weather, this behaviour contributes to increased space heating loads through uncontrolled air leakage driven by stack effect. It also makes it even more difficult to control the temperatures within the building generally.

Based on the temperature and differential pressure data collected as well as the equation for stack pressure (page 269 of [26]), it was determined that the monitored suites were located slightly below the neutral pressure plane. The temperature and differential pressure data from Suite 12 on January $24^{\text {th }}, 2013$ were used to provide an example of the effects of stack action. The pressures driving exfiltration and infiltration at the top and bottom of the building on this day were estimated at $+26 \mathrm{~Pa}$ and $-50 \mathrm{~Pa}$, respectively, with reference to the interior of the 
building. In calculating these pressure differences it was assumed that there was little resistance to air flow between the floors. Further, it was assumed that the effect of mechanical equipment on the differential pressures across the envelope was negligible. Stack pressures of the magnitude calculated here are similar to those measured in a study of pressure differences in MURBs conducted by the CMHC [27]. Without the use of an air flow network model, these data cannot be used in the energy model. Nevertheless, these data are helpful in understanding how the current systems are functioning prior to contemplating various retrofit options.

The ventilation system in the subject building is primarily designed to prevent the cross-contamination of smoke and odours between suites by positively pressurizing the corridors. However, the effectiveness of this strategy depends on the ability of the supply fan to overcome stack effect. A correlation of the differential pressures between the corridor and the suites and the exterior temperature showed that, with colder temperatures, corridors became negatively pressurized. This is the opposite of the design intent of the system. However, despite the seemingly ineffectual corridor ventilation system, the monitored suites still appear to be well ventilated. Based on the monitored negative pressure of the suites with respect to the exterior and the observed window operation, fresh air is likely supplied primarily through uncontrolled infiltration.

While this additional monitoring data provides some insights into building performance, the parameters that can be used directly in model calibration are limited. The two most important pieces of information gleaned from the monitored data collected are: the interior temperatures, and the estimated electricity use breakdown between suites and common areas. Rather than relying on the model defaults in eQUEST, these collected data can be inputted directly into the energy model. It was expected that, with these data, the model accuracy would be improved.

\section{Model Calibration using the Refined Approach}

The Refined Approach model included three major changes from the Traditional Approach model. Instead of a standard weather file, a weather file reflecting the actual weather conditions that the building was exposed to during the data collection period was used. As well, the zone temperatures and the ratio of common area and suite-based electricity use were based on the data collected. 
A custom weather file was created using the roof-top weather station data. Also, the heating system operation dates were provided by the building manager: April $26^{\text {th }}, 2012$ to May $14^{\text {th }}, 2012$ and September $20^{\text {th }} 2012$ to April $25^{\text {th }} 2013$.

The zone temperature set points were increased from the defaults so that the average zone temperatures were equal to the average monitored temperatures in each season. Average temperatures of the monitored suites were assumed to be constant for the entire building. In reality, since the monitored suites were close to the neutral pressure plane, the suites above would be likely warmer while the suites below the neutral pressure plane would likely be cooler than the suite average during the heating season.

Using the estimates of the split between suite-based and common area electricity consumption, the loads assigned to the "residential" zones were decreased while the common area loads including corridors, office space and the day care were increased.

The changes made to the model during the re-calibration are summarized in Table 4. Changes to the electricity intensity and set point temperatures were based directly on the monitored data. However, changes to the DHW consumption and the loop capacities were adjusted without the benefit of data to improve the model fit. The heating- and cooling-related energy consumption from each model were compared with the difference in the heating and cooling degree-days between the model weather files to ensure that the incremental changes in energy end-use were reasonable. However, during the recalibration, higher natural gas consumption was required to meet the summertime consumption associated with DHW. It should be noted that occupant density, DHW schedules, and DHW equipment are identical in both models. Thus, this component of natural gas consumption should be identical. The authors cannot explain why this adjustment to the model was necessary to improve the refined prediction. Figure 9 shows the modeled energy consumption from the Refined Approach, the monitored energy consumption, and, for reference, the utility bill consumption normalized to CWEC from the Traditional Approach model. The CVRMSE and NMBE for the Refined Approach model are shown in Table 5 along with these indicators for the Traditional Approach model. Note that the positive and negative errors cancel out during calculation of the NMBE, so the lower NMBE associated with electricity consumption in the Traditional Approach 
does not necessarily indicate a model that is more reflective of actual building performance. Also shown in Table 5 is a comparison between the Traditional Approach model and the monitored data collected from the subject building. It is clear that the Traditional Approach model is a reasonable representation of the utility data normalized to the standard weather year. However, it is not sufficiently representative of the actual building performance as indicated by the exceeded limits specified in ASHRAE Guideline 14.

The model calibrated with the additional monitoring data provided electricity and natural gas profiles that more closely matched the actual consumption. However, these indicators do not capture how well the models reflect the monitored electricity use breakdown and suite temperatures, which is discussed in Section 9.

\section{Discussion}

The objective of this work was to determine the incremental benefit of building monitoring prior to energy model development. Thus, this discussion focuses on the two parameters that positively influenced the accuracy of the energy model: suite temperatures and sub-metered electricity consumption. Use of a weather file with actual data versus standard weather data is also addressed.

The modeled energy end-uses from both the Traditional and Refined Approaches are compared in Figure 10. The difference in heating and cooling loads can be attributed to the differences in the number of heating and cooling degree-days in the two weather files. The difference in DHW load can be attributed to the need to adjust the DHW consumption per person for recalibration of the Refined Approach model during the summer months. As the electricity consumption data derived from the utility bills were not weather normalized, some of the electricity consumption was not allocated to space conditioning in the Traditional Approach model. The Refined Approach model indicates that the electricity required for cooling was actually greater than indicated by the Traditional Approach model.

To examine energy-use from a different perspective, Figure 11 shows the contribution of each building component and system to the total building heat losses. The total heat losses are equal to the total energy input including natural gas and electricity, as well as solar, infiltration and occupancy gains. In other words, the total energy-use in 
Figure 10 is based on only utility consumption while the total energy-use in Figure 11 is based on utility consumption in addition to solar, infiltration and occupant gains. Envelope component losses, infiltration and DHW losses were determined from the eQuest simulation reports. Ventilation losses were estimated as the total energy input minus the envelope, infiltration and DHW losses. Due to the method used to determine the ventilation energy loss and the resulting magnitude, there was uncertainty about how the model split energy use between ventilation and infiltration. Without any additional data to refine the model, the infiltration and ventilation losses were combined.

The higher proportions of infiltration, window and wall losses from the Traditional Approach occur for two primary reasons: the greater number of HDDs in the CWEC weather file and the increased suite-based electrical loads compared with common area loads. The suspected cause of the difference in ventilation loss proportions is due to zone temperatures differences. Further analysis of the impact of changes to zone temperature and electricity use are presented here.

\subsection{Suite-based electricity use}

Without extensive sub-metering of major pieces of equipment and consumption in specific zones, determining electricity end-uses for the purposes of energy modeling is challenging. With the availability of the suite-based electricity consumption data gathered during the monitoring period, the split between suite-based and common area electricity use was found to be different than the eQUEST program defaults in the Traditional Approach model. Suite-based electrical loads were $54 \%$ of the total electrical load in the Traditional Approach model but were only $42 \%$ in the Refined Approach model. A similar result was found by Hanam et al. [5] where suite-based electrical loads were over-estimated prior to calibration with metered suite-based electricity consumption data. That said, the program defaults may be appropriate for some buildings and will likely be used when these data are not available. Regardless, the change to the suite-based electricity intensity in this model is an important refinement because it shows that the majority of the electricity use is under the control of the building owner not the suite occupants. This finding can influence next steps and potential retrofit strategies. For example, the building owner may opt to sub-meter major electrical loads to determine the most effective energy reduction strategy rather than embark on an energy-use reduction or light bulb exchange program for residents. 


\subsection{Zone Temperatures}

The set point temperature of a building can significantly affect energy consumption [28], so it is important to gather this data for energy modeling purposes. The temperatures using the eQUEST defaults in the Traditional Approach model were up to $5^{\circ} \mathrm{C}$ lower than the suite temperatures used in the Refined Approach model. For comparison, the Traditional Approach model was run with the actual weather file from the monitoring period and was found to use $26 \%$ less natural gas. By comparing the natural gas consumption between this new model and the two existing models, it was determined that about $17 \%$ of the natural gas reduction was due to a decrease in the weather file heating degree-days. This is consistent with the difference in the heating degree-days between the monitoring period and the standard weather year. The remaining $9 \%$ was due to a combination of the lower set point temperatures and the higher waste heat from the suite-based electrical loads.

\section{Conclusions and Recommendations}

Using whole-building energy consumption data derived from monitoring paired with a customized local weather file from the one-year monitoring period eliminated the errors associated with calendarization and weather normalization of the utility bill data. The monitored suite temperatures were found to be up to $5^{\circ} \mathrm{C}$ higher than the default temperatures which affected the variable natural gas consumption. Sub-metering of suites on different orientations, that included suites with and without A/C, was useful in developing an estimate of the average electricity intensity for all suites in the building $\left(45 \mathrm{kWh} / \mathrm{m}^{2}\right)$. However, sub-metering of major mechanical equipment would also have been helpful in further defining the common area plug, lighting and equipment loads.

A comparison of the modeled and measured energy consumption data showed that the Refined Approach model fit the monitored data slightly better (CVRMSE: 10.9\%) than the Traditional Approach model fit the processed utility data (CVRMSE: 12.0\%). More importantly, a comparison between the Traditional Approach model and the monitored data showed a poorer fit (CVRMSE: 22.3\%), indicating the limitations of the Traditional Approach.

Improving the performance of our existing buildings is one of the keys to reducing the energy and environmental impact of our buildings. In order to promote implementation of energy retrofits on a broad scale, estimates of retrofit energy savings must be accurate. Determining an accurate baseline energy model is the first step to 
developing a realistic estimate of retrofit measure performance and additional data such as monitored temperatures and electrical sub-metering can make these estimates more representative of actual performance.

\section{Acknowledgements}

The authors gratefully acknowledge the assistance provided by the University of Toronto's Director of Student Family Housing, Gloria Cuneo, and the Subject Building Operations Manager, Fraser Anderson, as well as the funding provided by the Natural Sciences and Engineering Research Council (NSERC) and the Neil B. Hutcheon Bequest.

\section{References}

[1] M.F. Touchie, C. Binkley, K.D. Pressnail, Correlating energy consumption with multi-unit residential building characteristics in the city of Toronto, Energy and Buildings 66 (2013) 648-656.

[2] T.A. Reddy, Literature review on calibration of building energy simulation programs: uses, problems, procedures, uncertainty and tools, ASHRAE Transactions 112 (2006) 226-240.

[3] L.G. Swan, V.I. Ugursal, Modeling of end-use energy consumption in the residential sector: A review of modeling techniques, Renewable and Sustainable Energy Reviews, 13 (2009) 1819-1835.

[4] Canada Mortgage and Housing Corporation, Field Testing to Characterize Suite Ventilation in Recently Constructed Mid- and High-Rise Residential Buildings, 1998.

[5] B. Hanam, G. Finch, C. Hepting, Metered calibrated energy simulation of high rise residential buildings: lessons learned, presented at the $13^{\text {th }}$ Canadian conference on buildings science and technology, Winnipeg, MB, 2011.

[6] I. Danielski, Large variations in specific final energy use in Swedish apartment buildings: Causes and solutions, Energy and Buildings, 49 (2012) 276-285.

[7] Natural Resources Canada. Energy Use Data Handbook Table: Residential Apartment Secondary Energy Use by Energy Source and End-Use. Retrieved September 20, 2012, Available from http://oee.nrcan.gc.ca/corporate/statistics/neud/dpa/tableshandbook2/res_00_4_e_5.cfm?attr=0 
[8] Natural Resources Canada, Table 38: Apartments Secondary Energy Use and GHG Emissions by Energy Source, 2008.

[9] T.A. Reddy, I. Maor, C. Panjapornpon, Calibrated detailed building energy simulation programs with measured data - Part I: General methodology (RP-1051), HVAC\&R Research, 13.2(2007) 221-241.

[10] D. Hubler, K. Tupper, E. Greensfelder, Pulling the levers on existing buildings: A simple method for calibrating hourly energy models, ASHRAE Transactions, 116 (2010) 261-268.

[11] Energy Management and Research Associates, Energy use and domestic hot water consumption, Energy Authority Report 94-19, 1994.

[12] Canada Mortgage and Housing Corporation, Analysis of the Annual Energy and Water Consumption of Apartment Buildings in the CMHC HiSTAR Database, Technical Series 01-142

[13] American Society of Heating, Refrigerating and Air-Conditioning Engineers, ASHRAE Guideline 14-2002 Measurement of Energy and Demand Savings.

[14] Davis Instruments, Wireless Vantage Pro2 ${ }^{\text {TM }} \&$ Vantage Pro2 ${ }^{\text {тM }}$ Plus Stations, Accessed July 5, 2013, Available at: http://www.davisnet.com/product_documents/weather/spec_sheets/6152_62_53_63_SS.pdf

[15] Triacta Power Technologies Inc., PowerHawk Smart Meters 6 X20 High Density Meters, Accessed July 5, 2013, Available at: http://www.triacta.com/tm/datasheets/Triacta-6X20-High-Density-Meter.pdf

[16] Structure Monitoring Technology, A2 Wireless Data Loggers, Accessed July 5, 2013, Available at: http://smtresearch.ca/products/a2-wireless-data-loggers

[17] D. Hart, Energy and water consumption load profiles in multi-unit residential buildings, Technical Series 05119, Research Highlights Canadian Mortgage and Housing Corporation, 2005.

[18] H. Bagge, D. Johansson, Measurements of household electricity and domestic hot water use in dwellings and the effect of different monitoring time resolution, Energy, 36 (2011) 2943-2951. 
[19] N. Saldanha, I, Beausoleil-Morrison, Measured end-use electric load profiles for 12 Canadian houses at high temporal resolution, Energy and Buildings, 49 (2012) 519-530.

[20] M. Kavgic, A. Summerfield, D. Mumovic, Z.M. Stevanovic, V. Turanjanin, Z.Z. Stevanovic, Characteristics of indoor temperatures over winter for Belgrade urban dwellings: Indications of thermal comfort and space heating energy demand, Energy and Buildings, 47 (2012) 506-514.

[21] Y. Jian, Y. Guo, J. Liu, Z. Bai, Q. Li, Case study of window opening behaviour using field measurement results, Build Simulation, 4 (2011) 107-116.

[22] X.S. Damianos, A.R. Day, M.S. Ratcliffe, The development of a dynamic model to simulate boiler controls, Building Services Engineering Research and Technology, 28(2)(2007) 105-116.

[23] T. Cholewa, A. Siuta-Olcha, M. A. Skwarczynski, Experimental evaluation of three heating systems commonly used in the residential sector, Energy and Buildings, 43(2011) 2140-2144.

[24] E. Burnett, W. Knowles, G. Finch, M. Dell, Energy Consumption in Mid- to High-Rise Residential Buildings Before and After Enclosure Rehabilitation - A Top-Down Approach, presented at the $13^{\text {th }}$ Canadian conference on buildings science and technology, Winnipeg, MB, 2011.

[25] American Society of Heating, Refrigerating and Air-Conditioning Engineers, ASHRAE Standard 55-2010 Thermal Environmental Conditions for Human Occupancy.

[26] N.B. Hutcheon, G.O.P. Handegord, Building Science for a Cold Climate, Institute for Research in Construction, 1995.

[27] Canada Mortgage and Housing Corporation, Assessment of Suite Compartmentalization and Depressurization in New High-Rise Residential Buildings, Technical Series 05-112, October 2005.

[28] C. Leung, H. Ge, Sleep thermal comfort and the energy saving potential due to reduced indoor operative temperature during sleep, Building and Environment, 59 (2013) 91-98. 